Research Paper:

\title{
The Viewpoint of Mothers on Pain Management in Neonatal Intensive Care Units
}

\author{
Mohammad Arshadi Bostanabad ${ }^{1}$ (D), Samaneh Alizadeh² ${ }^{\text {(D) }}$, Hossein Namdar Areshtanab $^{3}$ (D), Soraya Nemati ${ }^{* *}$ (i) \\ 1. Department of Peadiatrics Nursing, Faculty of Nursing and Midwifery, Tabriz University of Medical Sciences, Tabriz, Iran. \\ 2. Department of Medical-Surgical Nursing, Student Research Committee, Faculty of Nursing \& Midwifery, Tabriz University of Medical Sciences, Tabriz, Iran \\ 3. Department of Psychiatric-Nursing, Faculty of Nursing and Midwifery, Tabriz University of Medical Sciences, Tabriz, Iran. \\ 4. Sina Treatment and Educational Center, Tabriz University of Medical Sciences, Tabriz, Iran.
}

\begin{tabular}{|l|l|}
\hline $\begin{array}{l}\text { Use your device toscan } \\
\text { and read the article online }\end{array}$ & $\begin{array}{l}\text { Utitsion: Arshadi Bostanabad, M., et al., 2019. The Viewpoint of Mothers on Pain Management in Neonatal Intensive Care } \\
\text { Units. Journal of Client-Centered Nursing Care, 5(2), pp. 123-130. https://doi.org/10.32598/JCCNC.5.2.123 }\end{array}$ \\
\hline
\end{tabular}

\section{(c) (1) (8)}

Article info:

Received: 13 Oct 2018

Accepted: 02 Mar 2019

Published: 01 May 2019

Keywords:

Pain management,

Mothers, Infants,

Neonatal Intensive Care

Unit (NICU)

\section{A B S T RA C T}

Background: Parents play a vital role in the assessment and management of pain. There is limited knowledge about parental viewpoint or their participation in the pain management of the neonates admitted to the intensive care units. The present study aimed to assess the viewpoints of mothers about the pain management of neonates/ infants admitted to Tabriz hospitals.

Methods: It was a descriptive cross-sectional study. A total of 255 mothers whose infants had been admitted to Neonatal Intensive Care Units (NICU) were recruited by convenience sampling method from September 2016 to August 2017. The required data were collected using a demographic questionnaire and PAIN questionnaire-Neonatal Intensive Care. The obtained data were analyzed using descriptive statistics in SPSS.

Results: The Mean \pm SD age of the mothers was $28.38 \pm 6.10$ years, and the majority of them (39\%) had diploma. Among the mothers, $73 \%$ believed that their infants had experienced pain during admission to NICU. However, only $19 \%$ of the mothers stated that nurses tried to find the signs of pain in their infants; the majority of mothers $(80 \%)$ indicated that to some extent, they were satisfied with the information they received from the treatment team regarding pain control for their newborns.

Conclusion: Despite the prevalence of pain phenomenon in neonates, mothers' education for the symptoms of pain in their infants was inadequate. It seems that the mothers' participation in the pain management of their newborns makes them more capable of caring after discharge from the hospital. The study makes important findings available for future research.

\footnotetext{
* Corresponding Author:

Soraya Nemati, MSc.

Address: Sina Treatment and Educational Center, Tabriz University of Medical Sciences, Tabriz, Iran.

Tel: +98 (914) 1762439

E-mail: nematisina20@gmail.com
} 


\section{Highlights}

- Infant pain is among the stress sources in the mothers of infants admitted to NICU.

- Mothers' education for the symptoms of pain in their infants is inadequate.

- Most of the mothers obtain pain control information from nurses.

- Most pain relief information is obtained orally.

- Most mothers are satisfied with neonate pain management information provided by nurses.

\section{Plain Language Summary}

Parents play a key role in the management of pain. Furthermore, mothers of infants admitted to NICU are concerned about their infants' pain. Mothers' education on the symptoms of infant pain is inadequate. Most of the mothers obtain pain control information from nurses, orally. Stroking or rocking is the most frequent method of pain relief taught by nurses and mothers believe that therapeutic method reduces pain a lot. However, most mothers are satisfied with the received information. Concerning the importance of managing pain in infant, providing mothers with newborns' pain management, adequate training is needed to educate mothers about pain symptoms to make them more effective in post-discharge care.

\section{Background}

he International Association for the Study $\Gamma$ of Pain has defined the word "pain" as an unpleasant sensory and emotional experience associated with tissue damage that is always subjective (Carter \& Brunkhorst 2017) and given its importance in human health, it is recognized as the fifth most important symptom (Witt et al. 2016). Moreover, pain in hospitalized newborns, usually results from diagnostic and therapeutic interventions which has immediate, short-term and long-term effects, and evidence-based studies emphasize the long-term effects of pain on neurodevelopment of infants admitted to NICU; in other words, it is considered as one of the causes of attention, learning and behavioral disorders in this group of newborns (Tarjoman et al. 2019).

Pain management means to minimize the severity and duration of pain and to carry out interventions that have maximum impacts with minimal risks in this area (Fleishman \& Mayock 2018). Pain management is a very important indicator in the assessment of the quality of care (Filippa et al. 2019). To facilitate pain management in children, four principles have been identified including participation of mother and child in the diagnosis and relief of pain, timely availability of medical staff and parents, proper relationship between the nurses and the patient, and the supportive and educational role of nurses (Aziznejadroshan et al. 2016).
In general, parents are satisfied by following three components of participation, efficiency and competence, and interpersonal relationships with staff regarding infants' care (Russell et al. 2014).

Considering the fact that families play a key role in the assessment and management of pain, the importance of parental involvement in pain management of infants is well documented and the study of parental roles in examination and management of infants' pain have led to a change in the principles of health care. Moreover, parental encouragement and support has led them to participate in caring for the pain of their children. Parents also play an important role in helping health care professionals to understand the pain of infants and to provide them with relief. Nursing for newborns is the leading component for family-based care, but the involvement of the family in taking care of infants' pain is insufficient comparing to other aspects of care (Franck, Oulton \& Bruce 2012). Moreover, studies have shown that more participation of parents in the management of their newborns' pain in intensive care units makes them more capable in managing pain after discharge. However, parental viewpoint regarding pain management varies and there is not much knowledge about parental viewpoint or their participation in caring for the pain of infants who are admitted to NICU (Marfurt-Russenberger et al. 2016).

Parents' viewpoint of pain and its management is related to their experiences of pain and pain management, in- 
cluding expectations, participation (knowledge and participation in care) and satisfaction (personal evaluation of health services and health care providers) (Venegas et al. 2019). Over the past 15 years, research has begun to describe parental viewpoints regarding infants' pain management and the use of non-pharmacological pain relief methods. Frank et al., examined parental viewpoints on child pain management and concluded that parental involvement is low for infants' pain control; also parents in their study expressed that they play an inactive and passive role in managing infants' pain, with only a few satisfied parents with the pain management of their children (Franck et al. 2012).

Although professional guidelines and theoretical reasons emphasize that parents should be encouraged and supported to participate in caring for their infants' pain, there is not enough information about the parental viewpoints regarding pain management of newborns in Iran, and as long as there is no better understanding of parents' expectations, knowledge, participation, or satisfaction with pain management of newborns, it is not possible to effectively implement the guidelines and standards for pain management in NICU. Also, the results of the findings have shown that there is a deep gap between the perception of individuals regarding parental expectations and participation, and their satisfaction with pain management in NICUs (Filippa et al. 2019). Therefore, given that the parents of infants admitted to NICU are worried that their babies would be in pain, this sense of worry and concern can cause more stress for parents (Bueno et al. 2018). Based on the probable effect of parental demographics on their attitude toward pain management (Guedj et al. 2014), the current study aims to examine mothers' viewpoints regarding neonatal pain management in NICUs of Tabriz province hospitals.

\section{Materials and Methods}

It was a descriptive cross-sectional study. The sample was the mothers whose newborns had been admitted to NICUs of Tabriz province hospitals. Data were collected from September 2016 to August 2017. Sample size was determined as 255 by reference to similar studies (Franck et al. 2012), considering 95\% confidence and $5 \%$ error, using "sample size for estimating ratio" formula. For this purpose, the mothers who had the ability to read and write in Farsi, had infants admitted to NICU for more than two days, during which the mother met their infant at least 3 times, and who did not have any previous experience with admission to NICU were selected using convenience sampling method.
After obtaining a referral from the Faculty of Nursing and Midwifery of Tabriz University and after obtaining agreements of the authorities of the Al-Zahra, Taleghani and pediatric hospitals of Tabriz province, the researcher collected data by explaining the purposes of the study to the mothers and also obtained their written consent; the researcher also assured that mothers' information would be confidential.

Data was collected by a demographic form and PAIN questionnaire-Neonatal Intensive Care. The maternal demographic questionnaire was about the demographic and social characteristics of the mother and the family, and the infant's specific characteristics questionnaire included infants' personal information such as gender, gestational age, and age of birth, birth weight, and neonatal diagnosis.

Parental viewpoint questionnaire on pain management which is called PAIN questionnaire-Neonatal Intensive Care, includes 12 questions based on pain and pain management, how parents participate in pain management and their satisfaction with the function of the treatment team and the information provided for parents, which is a combination of questions answered with yes or no, openended questions and questions on a Likert type scale. Frequency and percent of the answers to each question is recorded in this article. The nominal and content validity of the questionnaire has been confirmed based on the expert's views on pain and quality improvement (Axelin et al. 2015; Franck et al. 2012). This tool was developed in a prospective manner by a bilingual person specializing in English and Persian, and it was translated from English to Persian and vice versa. In the current study, the validity of the Persian version of PAIN questionnaire was determined based on the views of 10 professors and experts of the Faculty of Nursing and Midwifery and necessary changes were made. The reliability of the questionnaire was also confirmed. Data were analyzed using descriptive statistics (mean, standard deviation and frequency) using SPSS-PC version 24.

\section{Results}

The results showed that most neonates were in the gestational age of $32.73 \pm 4.27$ weeks. The majority of them (54\%) were males and 50 percent were the first child. Their most frequent diagnosis was prematurity and respiratory problems which was $75 \%$ (193) with a mean hospitalization of $18.15 \pm 15.15$ days. Findings also revealed that the Mean $\pm \mathrm{SD}$ age of mothers participating in the study was $28.38 \pm 6.10$ years, $86 \%$ (219) were housewives, and half of the mother (50.2\%) had one child. A 
Table 1. Assessing the perspective of mothers on pain and its management in NICU

\begin{tabular}{lccc}
\hline \multicolumn{1}{c}{ Mothers' Viewpoints } & \multicolumn{2}{c}{ No. (\%) } \\
\cline { 2 - 4 } & Yes & No & Do not Know \\
\hline $\begin{array}{c}\text { In your opinion, did your child felt pain when he/she was admitted to the } \\
\text { intensive care unit? }\end{array}$ & $184(72.2)$ & $40(15.2)$ & $31(12.2)$ \\
\hline $\begin{array}{c}\text { Did nurses show you how to understand whether your baby is in pain? } \\
\text { Does your baby receive any medicine for pain? }\end{array}$ & $46(18.1)$ & $208(82.9)$ & 107 (42) \\
\hline
\end{tabular}

part of the mother's viewpoints regarding pain and its management are shown in Table 1.

Of the mothers, 44.7 percent received a lot of oral information about pain control from the treatment team, and $11.4 \%$ received no oral information; 55 percent of the mothers had not received any written information from the treatment team. A total of 207 mothers (81\%) obtained the information from nurses, $13 \%$ from physicians and $10 \%$ from other sources. Nine percent of the mothers stated that nobody talked to them about pain control; while $81.3 \%$ were satisfied with the amount of information they received from treatment team for controlling their newborns' pain (Table 2 ); also $88 \%$ of the mothers received at least one method for pain relief from nurses (Figure 1). Also, mothers' opinions about the effect of analgesic drugs and relaxation methods on reducing the pain of the infant are shown in the Figure 2. Also, 79\% of the mothers said they would get help in less than 10 minutes if they needed regarding their infants' pain.

\section{Discussion}

It was shown that the mothers could understand their baby's pain, although no one has talked to them about the symptoms of neonatal pain. It is shown that $85 \%$ of arents could recognize that their baby is in pain (Franck et al. 2012). Although in our study very little written information was provided to the mothers, but a lot of oral information had been given about pain management and neonatal pain relief methods. In a study entitled "Barriers of non-pharmacological methods for pain control in children and strategies provided by nurses", nurses pointed out that too many hours of work, lack of time and heavy workload, nursing shortage, inadequate education, lack of re-training and absence of mothers during work are barriers to non-pharmacological control of pain (Mohebbi \& Azimzadeh 2014).

In a study which examined nurses' knowledge of nonpharmacological pain control methods for children, the results showed that $99 \%$ of nurses have not received any special education for these methods of pain management. Also, $82.6 \%$ of them mentioned lack of re-training as one of the reasons for not using these methods (Montirosso et al. 2016; Pölkki, Korhonen \& Laukkala 2018). Other studies have identified the lack of knowledge among nurses, as well as the their negative attitude towards experiencing pain in neonates as the main barriers to pain assessment and reduction (Pölkki et al. 2018;

Table 2. Frequency of mothers' satisfaction with the performance of the treatment team

\begin{tabular}{|c|c|c|c|c|c|c|}
\hline \multirow{2}{*}{$\begin{array}{l}\text { Mothers' View- } \\
\text { points }\end{array}$} & \multicolumn{6}{|c|}{ No. (\%) } \\
\hline & Totally Agree & Agree & $\begin{array}{c}\text { Somewhat } \\
\text { Agree }\end{array}$ & $\begin{array}{l}\text { Somewhat } \\
\text { Disagree }\end{array}$ & Disagree & $\begin{array}{c}\text { Totally } \\
\text { Disagree }\end{array}$ \\
\hline $\begin{array}{l}\text { I feel reassured } \\
\text { because I know the } \\
\text { staff can tell me } \\
\text { when my baby is in } \\
\text { pain }\end{array}$ & $68(26.7)$ & $44(17.3)$ & 59 (23.1) & $16(6.3)$ & $44(17.3)$ & $24(9.4)$ \\
\hline $\begin{array}{l}\text { I felt satisfied when } \\
\text { the nurses sooth my } \\
\text { baby }\end{array}$ & $167(65.7)$ & $36(14.2)$ & 43 (16.9) & $2(0.8)$ & $5(2)$ & $1(0.4)$ \\
\hline $\begin{array}{l}\text { When I am worried } \\
\text { about my baby's } \\
\text { pain, the staff sup- } \\
\text { ports me }\end{array}$ & $135(53.1)$ & 45 (17.7) & $53(20.9)$ & $3(1.2)$ & $14(5.5)$ & $4(1.6)$ \\
\hline
\end{tabular}


70

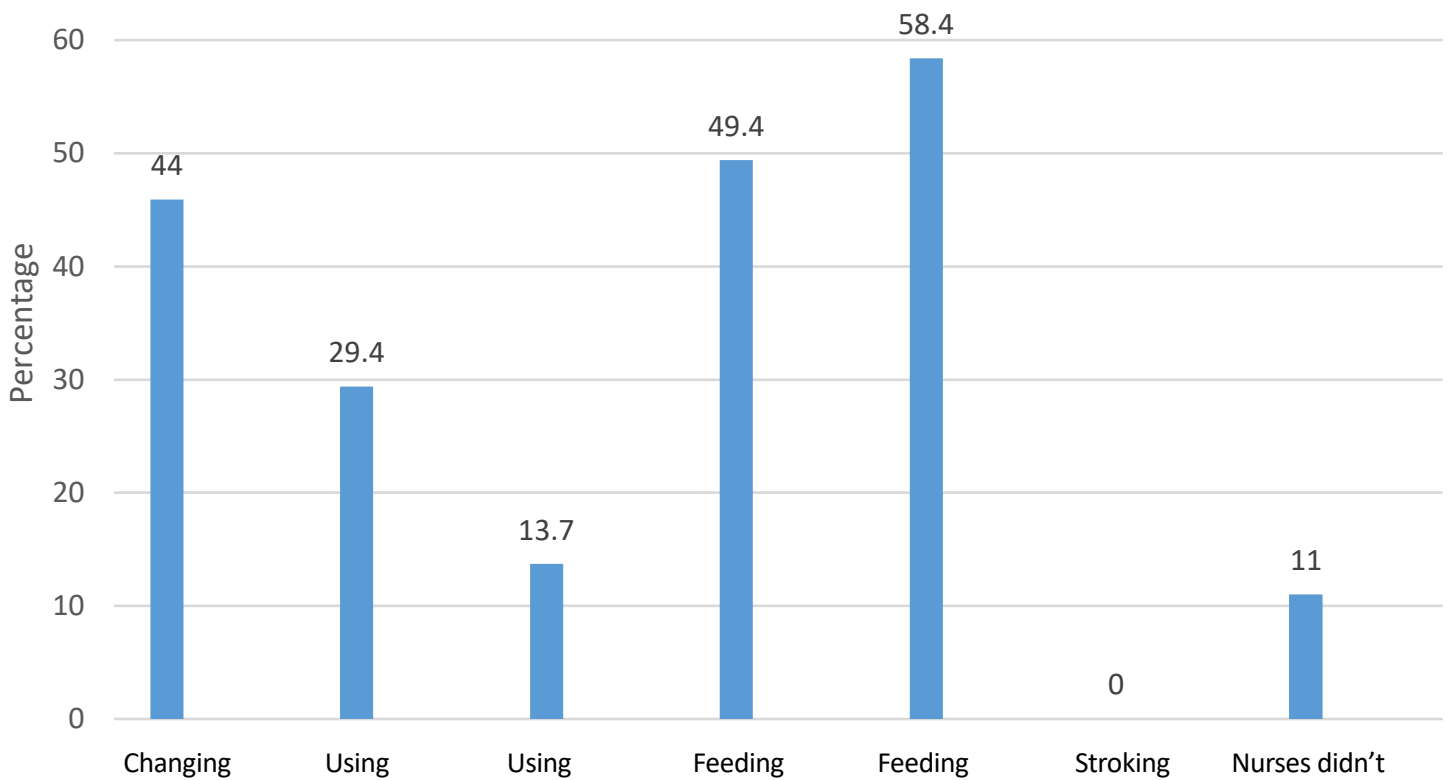

Figure 1. The frequency of methods taught by nurses to mothers for reducing pain

Client- Centered Nursing Care

Roué et al. 2017). However, it seems that the importance of infants' pain and its impact on the development of the babies has led nurses in NICUs to pay more attention to pain control and provide information that is more oral and takes less time.
The study also showed that stroking or rocking and changing the position of the baby were the most common soothing methods that had been thought by the nurses to mothers which may be due to the simplicity of these methods. The use of music was also the least common method that was used for this purpose; although the benefits of using music in controlling neonatal pain have

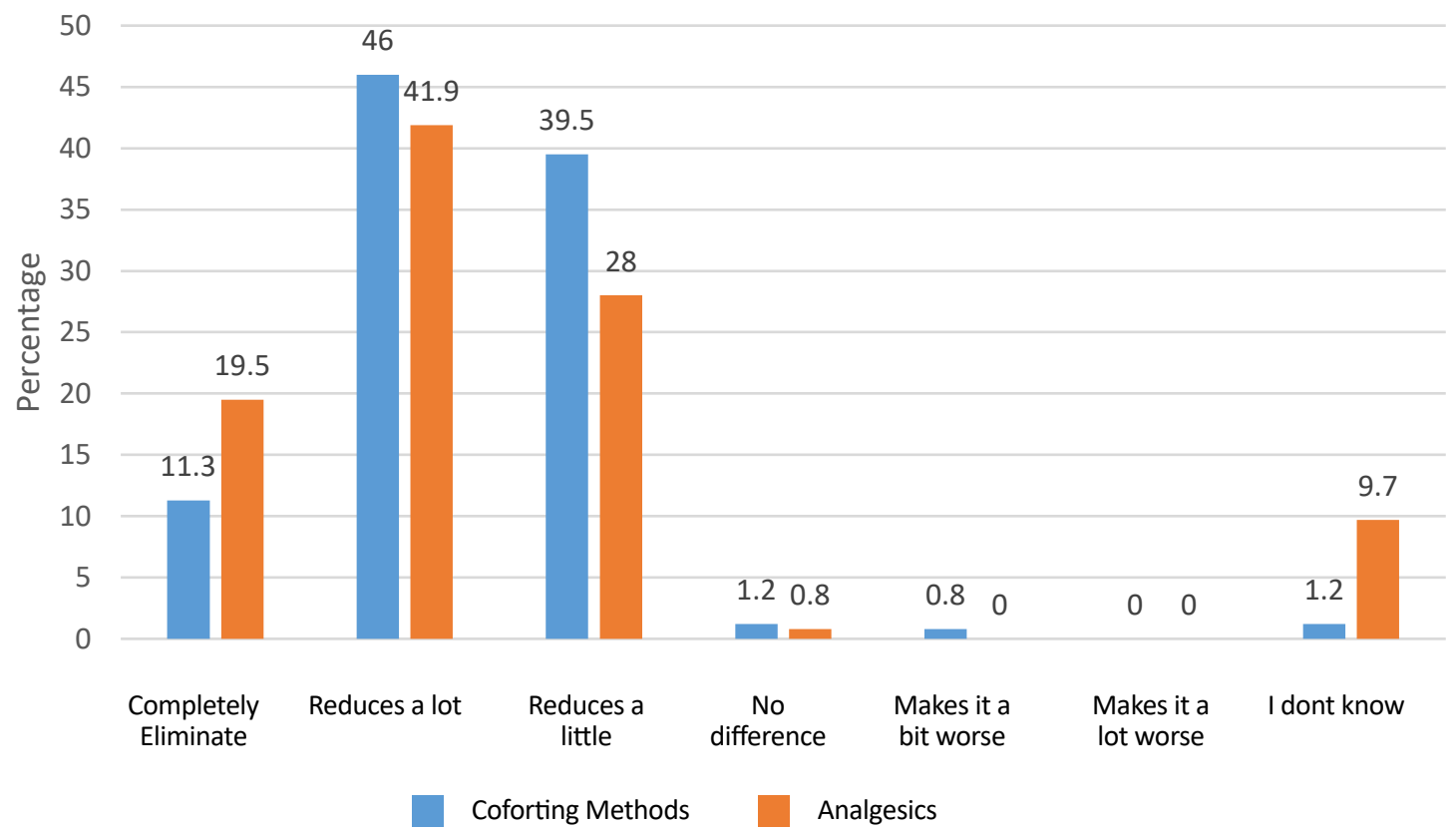

Figure 2. Comparing the effects of pain management methods from the mothers' viewpoints 
been well documented (Pölkki, Laukkala \& Korhonen 2016). However, it seems that due to the small space of NICU and accumulation of patients, the sound of music can be annoying for other babies, mothers and personnel. A study showed that stroking is the most common method, and music and feeding are the least common methods that were taught by nurses for pain management of newborns (Tarjoman et al. 2019).

It has been also indicated in a study that the most commonly taught method was changing the position of the baby and the least common ones were feeding and playing music. From the viewpoint of mothers, non-pharmacological pain control methods reduced the pain of their infants comparing to analgesics which can be due to the relationship between mothers and infants in the use of these methods. It is followed by mother's stress relief and creates a positive view regarding the use of non-pharmacological pain relief methods (Franck et al. 2012).

Studies also have shown that parental involvement in their newborn pain management facilitates their learning, transfers responsibility from nurses to parents, and creates attachment behaviors between parents and infants; although according to the findings of other studies, these are difficult to do in infant's unit (Venegas et al. 2019). Although mothers have desire to actively participate in the care of neonatal pain, parent participation and experiences before and during the admission to NICU are unique and nurses should consider these differences among mothers when they participate in caring for infants' pain (De Bernardo et al. 2017).

The current study also revealed that most of the mothers were satisfied with the amount of information they received from the treatment staff about pain management of their newborns. Research indicates that the need for knowledge and information about the infant and the need to acquire skills for infants' pain care had been introduced as primary educational needs by the parents of infants admitted to the NICU (Rasti et al. 2014). However, in the current study, the nurses provided most of the information to mothers, especially at the time of admission; so they were able to satisfy the mothers. The impact of teaching pain relief methods for infants on parental satisfaction had been examined and it has been shown that these trainings can be effective on the satisfaction of parents (Franck et al. 2011).

In Conclusion, The findings of this study showed that infant pain is one of the sources of stress in mothers of infants admitted to NICU. Despite the prevalence of pain phenomenon in neonates, mothers' education for the symptoms of pain in their infants was inadequate. Most of the mothers obtained pain control information from nurses and most of this information was oral. Stroking or rocking was the most frequent method of pain relief taught by nurses and the mothers believed that comforting methods reduce pain a lot. However, most of mothers were satisfied with the received information. Knowledge about mothers' perspectives on pain management in NICUs makes the personnel able to involve mothers in their babies' care and increase their satisfaction regarding pain management of their newborn. The study makes important findings available for future research.

\section{Ethical Considerations}

\section{Compliance with ethical guidelines}

Agreement of the Faculty of Nursing and Midwifery of Tabriz University and the authorities of the hospitals were obtained. Written consent was also obtained from the mothers, and they were assured that their information would be confidential.

\section{Funding}

This article is part of the master's thesis of Soraya Nemati, in the neonatal intensive nursing field in Tabriz University of Medical Sciences. Tabriz University of Medical Sciences provided facilities and support for this project.

\section{Authors' contributions}

All authors contributed in preparing this article.

\section{Conflict of interest}

The authors declared no conflict of interest.

\section{Acknowledgments}

The authors would like to thank the Vice-Chancellor of the Research Affairs of Tabriz University of Medical Sciences. We also appreciate the cooperation of the colleagues at Alzahra University, and Taleghani hospital and pediatric hospitals of Tabriz Province and all the mothers who participated in this project. We also thank Professor Linda Frank for her comments. 


\section{References}

Axelin, A., et al., 2015. Neonatal intensive care nurses' perceptions of parental participation in infant pain management. The Journal of Perinatal E Neonatal Nursing, 29(4), pp. 363-74. [DOI:10.1097/JPN.0000000000000136] [PMID]

Aziznejadroshan, P., Alhani, F., \& Mohammadi, E., 2016. Experiences of Iranian nurses on the facilitators of pain management in children: A qualitative study. Pain Research and Treatment, 2016(3594240), pp. 1-7. [DOI:10.1155/2016/3594240] [PMID] [PMCID]

Bueno, M., et al., 2018. Evaluation of a parent-targeted video in Portuguese to improve pain management practices in neonates. Journal of Clinical Nursing, 27(5-6), pp. 1153-9. [DOI:10.1111/jocn.14147] [PMID]

Carter, B. S., \& Brunkhorst, J., 2017. Neonatal pain management. Seminars in Perinatology, 41(2), pp. 111-6. [DOI:10.1053/j.semperi.2016.11.001] [PMID]

De Bernardo, G., et al., 2017. Supporting parents in taking care of their infants admitted to a neonatal intensive care unit: A prospective cohort pilot study. Italian Journal of Pediatrics, 43(1), p. 36. [DOI:10.1186/s13052-017-0352-1] [PMID] [PMCID]

Filippa, M., et al., 2019. Pain, parental involvement, and oxytocin in the neonatal intensive care unit. Frontiers in Psychology, 10, p. 715. [DOI:10.3389/fpsyg.2019.00715] [PMID] [PMCID]

Fleishman, R. A., \& Mayock, D. E., 2018. Neonatal pain and stress: Assessment and management. Avery's Diseases of the Newborn. Content Repository, pp. 432-45.

Franck, L. S., Oulton, K., \& Bruce, E., 2012. Parental involvement in neonatal pain management: An empirical and conceptual update. Journal of Nursing Scholarship, 44(1), pp. 45-54. [DOI:10.1111/j.1547-5069.2011.01434.x] [PMID]

Franck, L. S., et al., 2011. Parent involvement in pain management for NICU infants: A randomized controlled trial. Pediatrics, 128(3), pp. 510-8. [DOI:10.1542/peds.2011-0272] [PMID]

Guedj, R., et al., 2014. Does neonatal pain management in intensive care units differ between night and day? An observational study. BMJ Open, 4(2), p. e004086. [DOI:10.1136/bmjopen-2013-004086] [PMID] [PMCID]

Marfurt-Russenberger, K., et al., 2016. The experiences of professionals regarding involvement of parents in neonatal pain management. Journal of Obstetric, Gynecologic E Neonatal Nursing, 45(5), pp. 671-83. [DOI:10.1016/j.jogn.2016.04.011] [PMID]

Mohebbi, P., \& Azimzadeh, R., 2014. [Barrier of implementing non-pharmacological pain management in children and presented intereventions by nurses (Persian)]. Journal of Holistic Nursing and Midwifery, 24(2), pp. 40-8.

Montirosso, R., et al., 2016. Neonatal developmental care in infant pain management and internalizing behaviours at 18 months in prematurely born children. European Journal of Pain, 20(6), pp. 1010-21. [DOI:10.1002/ejp.826] [PMID]

Pölkki, T., Korhonen, A., \& Laukkala, H., 2018. Parents' use of nonpharmacologic methods to manage procedural pain in infants. Journal of Obstetric, Gynecologic E Neonatal Nursing, 47(1), pp. 43-51. [DOI:10.1016/j.jogn.2017.10.005] [PMID]

Pölkki, T., Laukkala, H., \& Korhonen, A., 2016. Nurses' and parents' perceptions of parental guidance on using nonpharmaco- logical pain-relieving methods among neonates in the NICU. Pain Management Nursing, 17(4), pp. 272-80. [DOI:10.1016/j. pmn.2016.04.002] [PMID]

Rasti, M., et al., 2014. Specification of the educational needs of parents with premature infants admitted to neonatal intensive care unit. Journal of Modern Rehabilitation, 8(4), pp. 21-9.

Roué, J. M., et al., 2017. Eight principles for patient-centred and family-centred care for newborns in the neonatal intensive care unit. Archives of Disease in Childhood-Fetal and Neonatal Edition, 102(4), pp. F364-F368. [DOI:10.1136/archdischild-2016-312180] [PMID]

Russell, G., et al., 2014. Parents' views on care of their very premature babies in neonatal intensive care units: A qualitative study. BMC Pediatrics, 14, p. 230. [DOI:10.1186/1471-2431-14230] [PMID] [PMCID]

Tarjoman, A., et al., 2019. Pain management in neonatal intensive care units: A cross sectional study of neonatal nurses in Ilam City. Journal of Neonatal Nursing, 25(3), pp. 136-8. [DOI:10.1016/j.jnn.2018.08.006]

Venegas, C. L., et al., 2019. A parent-targeted and mediated video intervention to improve uptake of pain treatment for infants during newborn screening: A pilot randomized controlled trial. The Journal of Perinatal E Neonatal Nursing, 33(1), pp. 74-81. [DOI:10.1097/JPN.0000000000000386] [PMID]

Witt, N., et al., 2016. A guide to pain assessment and management in the neonate. Current Emergency and Hospital Medicine Reports, 4(1), pp. 1-10. [DOI:10.1007/s40138-016-0089-y] [PMID] [PMCID] 
This Page Intentionally Left Blank 